\title{
Comparison between intravitreal bevacizumab and posterior sub-tenon injection of triamcinolone acetonide in macular edema secondary to retinal vein occlusion
}

This article was published in the following Dove Press journal: Clinical Ophthalmology

\author{
Meng-Ju Tsai' \\ Yi-Ting Hsieh ${ }^{1,2}$ \\ Yi-Jie Peng' \\ 'Department of Ophthalmology, \\ Taipei Tzu Chi Hospital, Buddhist \\ Tzu Chi Medical Foundation, New \\ Taipei, Taiwan; ${ }^{2}$ Department of \\ Ophthalmology, National Taiwan \\ University Hospital, Taipei, Taiwan
}

Correspondence: Yi-Jie Peng Department of Ophthalmology, Taipei Tzu Chi Hospital, Buddhist Tzu Chi Medical Foundation, No. 289, Jianguo Rd., Xindian District, New Taipei 23।42, Taiwan

Tel +886266289779 ext 570I

Fax +886266289009

Email yjpeng225@gmail.com

\begin{abstract}
Aim: To compare the efficacy and safety between posterior sub-tenon injection of triamcinolone acetonide (PSTA) and intravitreal injection of bevacizumab (Avastin) (IVIA) in the treatment of macular edema secondary to retinal vein occlusion.

Patients and methods: A total of 45 eyes were retrospectively enrolled ( 23 eyes with intravitreal bevacizumab and 22 eyes with posterior sub-tenon triamcinolone acetonide). Main endpoints included logMAR of best-corrected visual acuity (BCVA), central macular thickness (CMT), and intraocular pressure (IOP) before and after treatment at 6 months.

Results: The mean logMAR improved from 0.78 to 0.56 at 6 months for intravitreal bevacizumab ( $p=0.001$ ), and from 0.91 to 0.79 and 0.87 at 3 and 6 months ( $p=0.038$ and 0.13 ), respectively, for sub-tenon triamcinolone acetonide. At 6 months, the BCVA was significantly better in the bevacizumab group ( $p=0.02$ ). Both groups' mean CMT significantly improved, from $478 \mu \mathrm{m}$ at baseline to $295 \mu \mathrm{m}$ at 6 months in IVIA group $(p<0.001)$ and from $419 \mu \mathrm{m}$ at baseline to $350 \mu \mathrm{m}$ in PSTA group ( $p=0.012$ ); however, this was not different between the groups at 6 months $(p=0.065)$. Recurrence of macular edema was not different between the groups either $(p=0.08)$. Poorer final vision was associated with poorer baseline BCVA and diagnosis of central retinal vein occlusion after adjustment for age and $\operatorname{sex}(p<0.001$ and 0.012 , respectively). Significant elevation of IOP was noted at 3 months in the PSTA group, but declined at 6 months compared with baseline ( $p=0.002$ and 0.41 , respectively).
\end{abstract}

Conclusion: Intravitreal bevacizumab seemed to achieve better visual acuity compared with posterior sub-tenon injections of triamcinolone acetonide at 6 months, while CMT was comparable. PSTA still resulted in transient IOP elevation.

Keywords: sub-tenon injections, macular edema, retinal vein occlusion, bevacizumab, triamcinolone acetonide

\section{Introduction}

Retinal vein occlusion is one of the most common retinal vascular diseases secondary to diabetic retinopathy. ${ }^{1}$ Dilated, tortuous retinal veins and intraretinal hemorrhages are the hallmarks of ocular presentations of retinal vein occlusion. Visual outcomes are closely related to the ischemic status and integrity of perifoveal capillaries. Macular edema and neovascularization are the major complications that lead to severe visual loss. The pathogenesis is not fully understood; however, anatomical narrowing of retinal vessel, particularly at arterial-venous crossing, ${ }^{2}$ crowding effect at the level of lamina cribrosa, and a number of inflammatory disorders that 
cause vascular endothelial damage with thrombus formation may contribute to vessel occlusion. ${ }^{3-5}$ Both VEGF and inflammatory cytokines as a result of retinal ischemia are responsible for the increase in vascular permeability and leakage. ${ }^{6-8}$ Treatment modalities for macular edema include macular laser photocoagulation, intravitreal injections of anti-VEGF agents and triamcinolone acetonide, dexamethasone implant, and pars plana vitrectomy. ${ }^{9-15}$ The Central Vein Occlusion Study showed that while grid laser reduced the angiographic evidence of edema, it did not lead to significant visual benefit. More recent studies have been focusing on steroid and anti-VEGF agents, both of which have been demonstrated to markedly improve visual and anatomical outcomes. ${ }^{16}$

To date, intravitreal steroid injections and anti-VEGFs agents are the mainstay of treatment, and both show similar efficacy in the resolution of macular edema with visual improvement. ${ }^{9-11,17-19}$ The outcomes of intravitreal steroid and bevacizumab were comparable for branch retinal vein occlusion (BRVO) and central retinal vein occlusion (CRVO) in the short term. ${ }^{20,21}$ In another study, intravitreal triamcinolone acetonide and intravitreal bevacizumab were also similarly effective in treating macular edema secondary to BRVO at 1 year. However, triamcinolone acetonide carries adverse effects of cataract progression, ocular hypertension, and glaucoma. Nearly $40 \%$ of patients had significantly elevated intraocular pressure (IOP) that required antiglaucoma agents after intravitreal triamcinolone acetonide. ${ }^{22,23}$ In contrast, noninvasive posterior sub-tenon injection of triamcinolone acetonide (PSTA) may lower the risk of these problems with maintenance of relatively high ocular levels of triamcinolone acetonide. ${ }^{24-26}$ Thus, our study aimed to compare the safety and efficacy of intravitreal injection of bevacizumab (Avastin) (IVIA) and PSTA in treating macular edema secondary to retinal vein occlusion.

\section{Patients and methods Study population}

We retrospectively enrolled a total of 45 eyes treated with either IVIA or PSTA for macular edema secondary to retinal vein occlusion with a minimum of 3 months follow-up. The inclusion criteria included 1) blurred vision due to macular edema attributable to retinal vein occlusion, diagnosed by fundus showing retinal venous tortuosity accompanied with flame-shaped or blot hemorrhage in at least one quadrant in BRVO or full four quadrants in CRVO, and/or presence of cotton wool spots or disc edema, 2) macular edema evidenced by optical coherence tomography (OCT) (Stratus; Carl Zeiss Meditec, Inc., Dublin, CA, USA) with central macular thickness (CMT) $250 \mu \mathrm{m}$ or greater and presence of intraretinal cyst or subretinal fluid. The exclusion criteria included 1) concurrent ocular pathology such as uveitis, age-related macular degeneration, diabetic macular edema, or other causes of macular edema, 2) patients with intravitreal injection of antiVEGFs, steroid, or any intraocular surgery 3 months prior to the inclusion. Injections would be repeated if there was any drop of visual acuity or persistent metamorphopsia, and/or macular edema with increase in CMT during follow-up. This research adhered to the tenets of the Declaration of Helsinki, and Institutional Review Board (IRB) approval was obtained from the IRB of Taipei Tzu Chi Hospital, Buddhist Tzu Chi Medical Foundation. This research involved no more than minimal risks to subjects and would not adversely affect the welfare of the subjects, and waivers to documentation of informed consent were approved by IRB of Taipei Tzu Chi Hospital, Buddhist Tzu Chi Medical Foundation. Data confidentiality was protected.

\section{Procedure for PSTA and IVIA}

The procedure for PSTA was modified according to the method described by Nozik. ${ }^{27}$ The patient was asked to direct his or her gaze superonasally, and an injection of $40 \mathrm{mg} / 1 \mathrm{~mL}$ of triamcinolone acetonide was administered inferotemporally into the posterior sub-tenon space with a 27 -gauge needle. In the IVIA group, bevacizumab $1.25 \mathrm{mg} / 0.05 \mathrm{~mL}$ (Avastin, Genentech, South San Francisco, CA, USA) was administered intravitreally under topical povidone-iodine sterilization with topical anesthesia and by using a sterile lid speculum.

\section{Data collection}

Best-corrected visual acuity (BCVA) was measured with the Snellen chart, CMT was measured with OCT at the innermost $1 \mathrm{~mm}$ diameter circle and IOP was measured with a noncontact tonometer at the time of first injection, 1, 3 and 6 months postoperatively. BCVA was converted to the logMAR for data analysis. Retreatment criteria for each group included persistent macular edema with intraretinal cyst or subretinal fluid, with or without any decrease in visual acuity during follow-up. Time to second injection, if any, was measured as a recurrence-free interval. Baseline characteristics of age, sex, diagnosis, and lens status were also recorded according to a chart review. Perfusion status was analyzed by the perifoveal capillary network seen in fundus fluorescein angiography, and nonperfusion status was defined by the contact of 
nonperfused macular with the foveal avascular zone, which has been mentioned in an earlier study. ${ }^{28}$

\section{Statistical analysis}

Paired $t$-test was used to analyze $\log$ MAR BCVA, IOP, and CMT values between baseline and 1, 3 and 6 months after treatment within each group. The Mann-Whitney $U$-test was used to analyze continuous variables between groups, and discrete variables were analyzed by $\chi^{2}$ or Fisher's exact test. Survival analysis using log rank test was performed to compare the first recurrence between groups. Multiple linear regression analysis was used to evaluate the prognostic factors for final BCVA. SPSS for Windows (Version 12; SPSS Inc., Chicago, IL, USA) was used for statistical analysis. A $p$-value $<0.05$ was considered statistically significant.

\section{Results}

\section{Baseline characteristics}

Clinical characteristics of the patients who met the initial criteria are shown in Table 1 . There were no significant differences with regard to age, sex, diagnosis, baseline logMAR BCVA, IOP, or CMT between the IVIA and PSTA groups (all $p>0.05$ ).

\section{Visual improvement}

In the IVIA group, the $\log$ MAR BCVA improved at $1-6$ months, from $0.78 \pm 0.46$ (mean $\pm \mathrm{SD}$ ) at baseline to $0.6 \pm 0.39$

Table I Baseline characteristics of patients with macular edema secondary to retinal vein occlusion

\begin{tabular}{|c|c|c|c|}
\hline Treatment groups & IVIA (n=23) & PSTA $(n=22)$ & $p$-value \\
\hline Age (years), mean (SD) & $63(13)$ & $70(13)$ & $0.07^{*}$ \\
\hline \multicolumn{4}{|l|}{ Sex, \% (n) } \\
\hline Male & $56.5 \%(13)$ & $68.2 \%(15)$ & $0.42 * *$ \\
\hline Female & $43.5 \%(10)$ & $31.8 \%(7)$ & \\
\hline \multicolumn{4}{|l|}{ Diagnosis, \% (n) } \\
\hline BRVO & $69.6 \%(16)$ & $77.3 \%(17)$ & $0.56^{* *}$ \\
\hline CRVO & $30.4 \%(7)$ & $22.7 \%(5)$ & \\
\hline Nonperfused PCN, \% & $40 \%(6 / 15)$ & $50 \%(6 / / 2)$ & $0.60 * *$ \\
\hline \multicolumn{4}{|l|}{ Lens status, \% (n) } \\
\hline Phakia & $17.4 \%(4)$ & $22.7 \%(5)$ & $0.72 * *$ \\
\hline Pseudophakia & $82.6 \%(19)$ & $77.3 \%(17)$ & \\
\hline Baseline BCVA, mean (SD) & $0.78(0.46)$ & $0.91(0.46)$ & $0.21 *$ \\
\hline Baseline IOP, mean (SD) & $14.4(3.1)$ & $12.8(2.9)$ & $0.08 *$ \\
\hline Baseline CMT, mean (SD) & $478(126)$ & 419 (125) & $0.09 *$ \\
\hline
\end{tabular}

Note: *Mann-Whitney U-test, ${ }^{*} \chi^{2}$ test or Fisher's exact test.

Abbreviations: BCVA, best-corrected visual acuity; BRVO, branch retinal vein occlusion; CMT, central macular thickness ( $\mu \mathrm{m})$; CRVO, central retinal vein occlusion; IOP, intraocular pressure ( $\mathrm{mmHg}$ ); IVIA, intravitreal injection of bevacizumab; PCN, perifoveal capillary network; PSTA, posterior sub-tenon injection of triamcinolone acetonide.
Table 2 Comparisons of primary outcome measures following treatment between groups

\begin{tabular}{|c|c|c|c|c|c|}
\hline $\begin{array}{l}\text { Outcome } \\
\text { measures }\end{array}$ & IVIA & $p$-value & PSTA & $p$-value & $\begin{array}{l}p \text {-value for } \\
\text { between } \\
\text { groups }\end{array}$ \\
\hline \multicolumn{6}{|c|}{ logMAR BCVA, mean (SD) } \\
\hline Baseline & $0.78(0.46)$ & & $0.91(0.46)$ & & 0.21 \\
\hline Month I & $0.60(0.39)$ & 0.006 & $0.81(0.49)$ & 0.16 & 0.09 \\
\hline Month 3 & $0.57(0.33)$ & 0.001 & $0.79(0.50)$ & 0.038 & 0.12 \\
\hline Month 6 & $0.56(0.36)$ & 0.001 & $0.87(0.47)$ & 0.13 & 0.02 \\
\hline \multicolumn{6}{|c|}{ CMT $(\mu \mathrm{m})$, mean $(\mathrm{SD})$} \\
\hline Baseline & $478(126)$ & & $419(125)$ & & 0.09 \\
\hline Month I & $272(94)$ & $<0.001$ & $347(103)$ & 0.002 & 0.006 \\
\hline Month 3 & $273(79)$ & $<0.001$ & $332(117)$ & 0.001 & 0.03 \\
\hline Month 6 & $295(113)$ & $<0.001$ & $350(1 \mid 5)$ & 0.012 & 0.065 \\
\hline
\end{tabular}

Abbreviations: BCVA, best-corrected visual acuity; CMT, central macular thickness $(\mu \mathrm{m})$; IVIA, intravitreal injection of bevacizumab; PSTA, posterior subtenon injection of triamcinolone acetonide.

at 1 month and $0.56 \pm 0.36$ at the last visit ( $p=0.006$ and 0.001 , respectively, by paired $t$-test). In the PSTA subgroup, the visual acuity did not improve until 3 months after injection, from $0.91 \pm 0.46$ at baseline to $0.79 \pm 0.5$ at 3 months ( $p=0.038$ ). However, the significance did not remain to the last visit $(p=0.13)$. IVIA had better BCVA at 6 months $(p=0.02)$. All results are shown in Table 2 .

\section{Reduction in CMT}

Both IVIA and PSTA groups had significant reduction in CMT from 1 to 6 months. In the IVIA group, the thickness improved from $478 \pm 126 \mu \mathrm{m}$ at baseline to $295 \pm 113 \mu \mathrm{m}$ at 6 months $(p=0.001)$. In the PSTA group, the thickness improved from $419 \pm 125 \mu \mathrm{m}$ at baseline to $350 \pm 115 \mu \mathrm{m}$ at 6 months $(p=0.012)$.

\section{IOP}

The results are shown in Table 3. In the IVIA group, the IOP seemed to be higher after 1 month of injection, changing from $14.4 \pm 3.1 \mathrm{mmHg}$ at baseline to $15.3 \pm 3.0 \mathrm{mmHg}$ at 1 month (borderline significant, $p=0.059$ ). The IOP was

Table 3 IOP after intravitreal Avastin or sub-tenon Kenacort treatment

\begin{tabular}{|c|c|c|c|c|c|}
\hline $\begin{array}{l}\text { IOP, mean } \\
\text { (SD) }\end{array}$ & IVIA & p-value & PSTA & p-value & $\begin{array}{l}p \text {-value for } \\
\text { between } \\
\text { groups }\end{array}$ \\
\hline Baseline & $14.4(3.1)$ & & $12.8(2.9)$ & & 0.08 \\
\hline Month I & I5.3 (3.0) & 0.059 & I4.4 (5.5) & 0.12 & 0.21 \\
\hline Month 3 & I 4.7 (3.6) & 0.66 & $16.0(4.4)$ & 0.002 & $0.4 I$ \\
\hline Month 6 & |4.0 (3.4) & 0.38 & |3.3 (3.3) & $0.4 I$ & 0.55 \\
\hline
\end{tabular}

Abbreviations: IOP, intraocular pressure $(\mathrm{mmHg})$; IVIA, intravitreal injection of bevacizumab; PSTA, posterior sub-tenon injection of triamcinolone acetonide. 


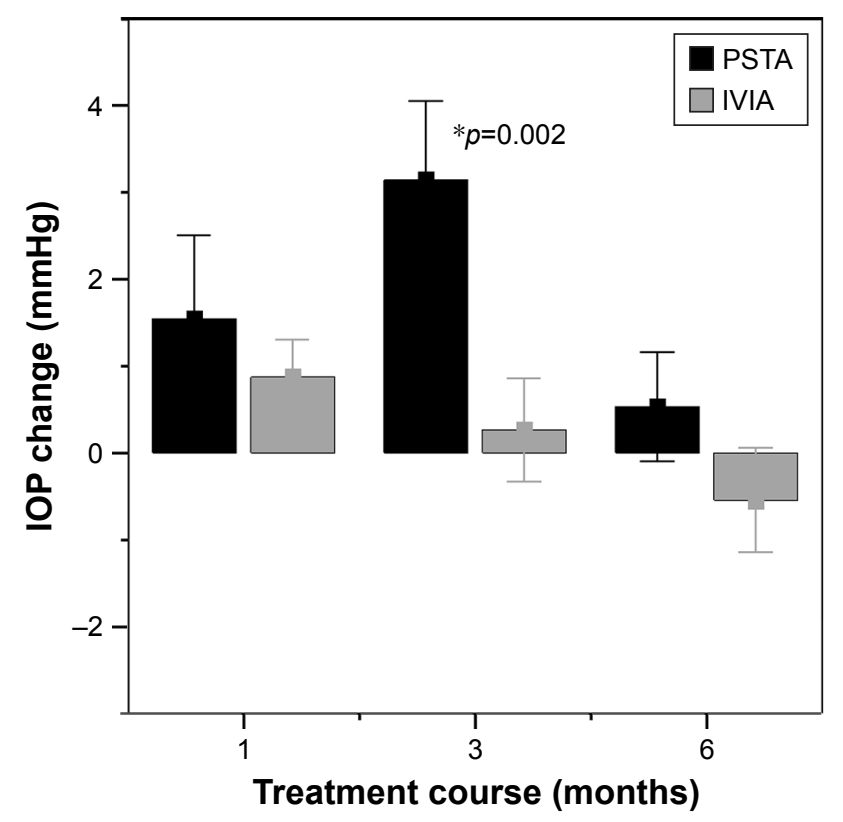

Figure I Graph representing the comparison of IOP change $(\mathrm{mmHg}$, mean $\pm \mathrm{SEM})$, mean between the 2 groups at I, 3 and 6 months following treatment.

Abbreviations: IOP, intraocular pressure; SEM, standard error of the mean.

not significantly elevated during each follow-up compared with baseline (all $p>0.05$ ). In the PSTA group, the IOP was significantly higher at 3 months, from $12.8 \pm 2.9 \mathrm{mmHg}$ at baseline to $16.0 \pm 4.4 \mathrm{mmHg}(p=0.002)$, but declined to $13.3 \pm 3.3 \mathrm{mmHg}$ at 6 months $(p=0.41)$ (Figure 1$)$.

\section{Number of injections}

The number of injections in IVIA was $1.5 \pm 0.8$, compared with $1.7 \pm 0.9$ in PSTA. This was not significant $(p=0.47)$.

\section{Recurrence of macular edema}

The time to second injection was $10.9 \pm 6.3$ weeks (mean \pm SD) in the IVIA group, compared with $6.5 \pm 4.2$ weeks in the PSTA group. The PSTA group had a shorter interval to the second injection, but this was not significant (log rank test, $p=0.08$ ) (Figure 2).

\section{Prognostic factors for final BCVA at 6 months}

After adjustment of age and sex for the linear regression model, we found that poorer baseline BCVA and diagnosis of CRVO predicted poorer visual acuity at 6 months $(p<0.001$ and 0.012, respectively). However, if baseline BCVA was adjusted in addition to age and sex, we found that neither diagnosis nor treatment regimen was significant for final BCVA at 6 months (Table 4).

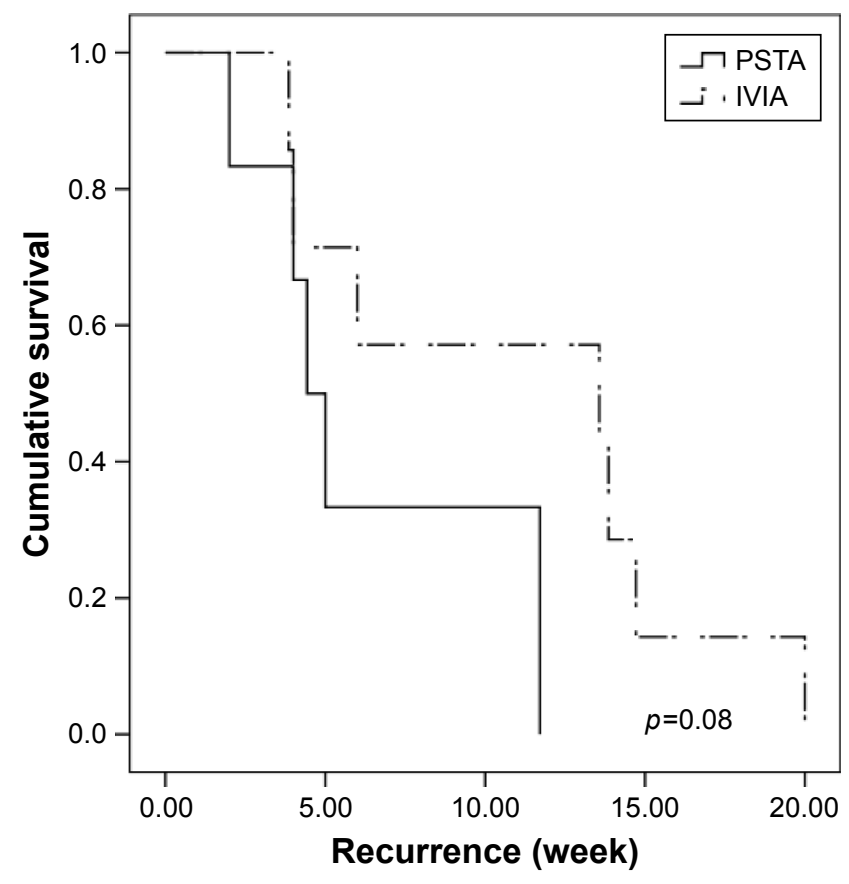

Figure 2 Kaplan-Meier survival analysis of first recurrence of macular edema. Note: The 2 curves represent the cumulative proportion of recurrence-free intervals for the IVIA and PSTA groups.

Abbreviations: IVIA, intravitreal injection of bevacizumab; PSTA, posterior subtenon injection of triamcinolone acetonide.

\section{Complications}

None of the complications such as endophthalmitis, vitreous hemorrhage or retinal detachment were noted during the 6 months. In the PSTA group, three cases had IOP $24 \mathrm{mmHg}$ or more during follow-up, but these events were controlled with antiglaucoma agents and all these cases returned to $21 \mathrm{mmHg}$ or lower IOP at the last visit. Other complications such as postoperative ptosis or cataract progression were not noted over the course of treatment.

\section{Discussion}

Macular edema remains one of the major vision-threatening complications for patients with retinal vein occlusion.

Table 4 Prognostic factors for BCVA at 6 months by linear regression analysis

\begin{tabular}{lllll}
\hline Clinical factors & Coefficient & p-value* & Coefficient & p-value** \\
\hline Age & 0.017 & 0.001 & 0.007 & 0.043 \\
Sex & -0.041 & 0.75 & -0.009 & 0.911 \\
Baseline BCVA & 0.754 & $<0.001$ & 0.78 & $<0.001$ \\
Diagnosis & -0.372 & 0.012 & -0.091 & 0.38 \\
Treatment & -0.219 & 0.16 & -0.118 & 0.22 \\
Lens status & -0.107 & 0.48 & -0.018 & 0.85 \\
\hline
\end{tabular}

Notes: ${ }^{*}$-value after adjustment for age and sex. ${ }^{* *} p$-value after adjustment for age, sex and baseline BCVA.

Abbreviation: BCVA, best-corrected visual acuity. 
Currently, intravitreal injections of triamcinolone acetonide and intravitreal anti-VEGF agents are the mainstay of treatment. A conclusion has not yet been reached as to which is superior to the other..$^{21,29-31}$ In one recent meta-analysis that included a total of 8 studies, both intravitreal injections of triamcinolone acetonide and intravitreal bevacizumab resulted in similar visual acuity for BRVO and CRVO at 24 weeks. ${ }^{32}$ Another retrospective study, however, showed that bevacizumab had better visual improvement than triamcinolone acetonide in BRVO in the initial 6 months, but the improvement was not sustained at 1 year. ${ }^{33}$ In that study, the CMT was not different between groups at all visits. Byun et $\mathrm{al}^{29}$ observed less recurrence in the group with triamcinolone acetonide compared with bevacizumab although the visual gain was comparable at 1 year.

To the best of our knowledge, no results have been published with regard to the comparison between anti-VEGF agents and sub-tenon injections of triamcinolone acetonide for macular edema in retinal vein occlusion. Sub-tenon injections of triamcinolone acetonide were effective in the resolution of macular edema, as reported in previous studies. Lin et $\mathrm{al}^{13}$ reported significant improvement after PSTA for both ischemic and nonischemic CRVO at each time point for a total of 9 months of follow-up. Another study also showed similar results in the short term. ${ }^{14}$ In that study, $79 \%$ of patients had an improvement of $>5$ letters at postoperative 4 weeks with just a single injection of PSTA, which was comparable to our study. Nevertheless, we found that the effect of PSTA was no longer sustained after 3 months. Compatible with what was found by Kola et al, ${ }^{34}$ PSTA exerted a short-term efficacy with significant visual improvement at 3 months, but disease recurred at 6 months, and the difference from baseline was no longer sustained ( $p=0.846$ ). The fading drug effect probably accounted for the observation. The concentration of triamcinolone acetonide may last for 3 months after injections. ${ }^{35}$ Additionally, we inferred that steroids are different from anti-VEGF agents in their mechanisms in that steroids may fail to directly block the existing VEGF molecules as bevacizumab does. Steroids probably take a longer time than anti-VEGF agents to produce a clinical effect by downregulating the expression of VEGF and other inflammatory cytokines such as interleukin 6 and interleukin 17 in endothelial cells. ${ }^{36,37}$ Taken together, it is plausible that intravitreal bevacizumab tended to lead to more rapid resolution of edema and earlier visual recovery than triamcinolone acetonide.

Intravitreal steroid injection may be associated with a higher risk of intraocular hypertension compared with posterior sub-tenon injection. ${ }^{24,26}$ In the SCORE studies, ${ }^{22,23}$ triamcinolone acetonide caused significantly elevated IOP that required IOP-lowering agents in up to $41 \%$ of patients with BRVO and $35 \%$ with CRVO. Gokce et $\mathrm{al}^{33}$ showed that $26.9 \%$ of BRVO patients on intravitreal triamcinolone acetonide had IOP above $30 \mathrm{mmHg}$. However, we observed that triamcinolone acetonide via posterior sub-tenon injections may still cause transient-marked IOP elevation at the point of time when steroid concentration could be measurable at 3 months as mentioned above. In the present study, 5 eyes $(22.7 \%)$ had ocular hypertension in the steroid group, with 2 eyes having an IOP of above $21 \mathrm{mmHg}$ and 3 eyes having IOP of above $24 \mathrm{mmHg}$ during follow-up. The 2 eyes with $<24 \mathrm{mmHg}$ but over $21 \mathrm{mmHg}$ underwent retreatment with a second injection at 2 and 5 weeks, respectively. Four of the 5 eyes controlled their IOP under topical medications. Another eye was lost follow-up at 6 months. None of the eyes in the bevacizumab group had IOP $>21 \mathrm{mmHg}$ over the course of treatment.

Counterintuitively, we observed that eyes with sub-tenon triamcinolone acetonide injections tended to have shorter time to second injection than those with bevacizumab injections by approximately 4 weeks, largely because we treated patients on a PRN basis rather than using a fixed number of injections. As mentioned earlier, triamcinolone acetonide may take a longer time to produce an effect by downregulating the expression of VEGF and other cytokines rather than directly binding to VEGF molecules. This may lead to more injections at early follow-up periods before steroids take their maximal effect. The previous study showed fewer injections with intravitreal triamcinolone acetonide than bevacizumab; ${ }^{29}$ however, the discrepancy may be attributed to different protocols used to treat both groups. They re-treated patients when CMT increased $>100$ $\mu \mathrm{m}$. In contrast, we re-treated patients with poorer visions even though there were only small rises of macular thickness, ie, $<100 \mu \mathrm{m}$. Moreover, different routes of injections also account for this finding. Sub-tenon injections reach the vitreous cavity more slowly than direct administration by intravitreal injections, particularly in nonvitrectomized eyes. ${ }^{38}$ Also, the exact locations of triamcinolone acetonide particles may be hard to predict under current practice, and this may affect treatment response. Optimal placement of triamcinolone acetonide particles within the sub-tenon spaces was observed in only $46 \%$ of eyes. ${ }^{39}$ It is plausible to assume that inferotemporal injections would probably have lower chance of optimal placement due to the lack of gravitational diffusion as observed in superotemporal injections to cover 
more areas over the macula. The modified procedure of using an intravenous cannula rather than a needle may be recommended to place steroid particles more properly and safely. ${ }^{40}$ As to complications, no cases of cataract progression or lid problems such as ptosis were noted after PSTA in our study. While ptosis after posterior sub-tenon injections may not be rare, it may either result from direct trauma to the levator aponeurosis or due to steroid-induced myopathy particularly with superotemporal injections. ${ }^{41,42}$ We inferred that injections from the inferotemporal site could possibly avoid direct penetration or reduce the contact of steroid to the levator complex.

There are a number of limitations in our study such as its retrospective nature and small number of cases with mixed BRVO and CRVO. We found that some post-PSTA treatment eyes were not enrolled in our study due to loss of follow-up over the course of treatment for varying reasons, particularly in those with relatively better visual acuity at baseline. On the other hand, we also did not know if the outcomes could be further improved after switching in either group with initial suboptimal response. Also, we did not completely analyze the results of macular perfusion status because fluorescein angiography was not routinely performed during follow-up. A further prospective trial with long-term follow-up and crossover design is necessary to compare the safety and efficacy of these 2 treatment modalities with an option of switching therapy for those with initial suboptimal response.

\section{Conclusion}

IVIA seemed to have better visual outcomes than PSTA, but the macular thickness did not differ significantly at 6 months. In addition, bevacizumab injections resulted in earlier visual recovery. Poorer baseline visual acuity may lead to poorer visual recovery. PSTA may still result in significant elevation of IOP at 3 months and decline at 6 months.

\section{Acknowledgment}

This study was supported by grants from the Taipei Tzu Chi Hospital, Buddhist Tzu Chi Medical Foundation (TCRDTPE-106-09).

\section{Disclosure}

The authors report no conflicts of interest in this work.

\section{References}

1. Rogers S, McIntosh RL, Cheung N, et al. The prevalence of retinal vein occlusion: pooled data from population studies from the United States, Europe, Asia, and Australia. Ophthalmology. 2010;117(2):313-319.e1.
2. Weinberg D, Dodwell DG, Fern SA. Anatomy of arteriovenous crossings in branch retinal vein occlusion. Am J Ophthalmol. 1990;109(3): 298-302.

3. Green WR, Chan CC, Hutchins GM, Terry JM. Central retinal vein occlusion: a prospective histopathologic study of 29 eyes in 28 cases. Retina. 1981;1(1):27-55.

4. Beaumont PE, Kang HK. Clinical characteristics of retinal venous occlusions occurring at different sites. Br J Ophthalmol. 2002;86(5): 572-580.

5. Kolar P. Risk factors for central and branch retinal vein occlusion: a metaanalysis of published clinical data. J Ophthalmol. 2014;2014:724780.

6. Noma H, Funatsu H, Yamasaki M, et al. Aqueous humour levels of cytokines are correlated to vitreous levels and severity of macular oedema in branch retinal vein occlusion. Eye (Lond). 2008;22(1):42-48.

7. Noma H, Minamoto A, Funatsu H, et al. Intravitreal levels of vascular endothelial growth factor and interleukin-6 are correlated with macular edema in branch retinal vein occlusion. Graefes Arch Clin Exp Ophthalmol. 2006;244(3):309-315.

8. Noma H, Funatsu H, Mimura T, Harino S, Hori S. Vitreous levels of interleukin- 6 and vascular endothelial growth factor in macular edema with central retinal vein occlusion. Ophthalmology. 2009;116(1): 87-93.

9. Campochiaro PA, Sophie R, Pearlman J, et al. Long-term outcomes in patients with retinal vein occlusion treated with ranibizumab: the RETAIN study. Ophthalmology. 2014;121(1):209-219.

10. Cekic $\mathrm{O}$, Chang $\mathrm{S}$, Tseng JJ, et al. Intravitreal triamcinolone treatment for macular edema associated with central retinal vein occlusion and hemiretinal vein occlusion. Retina. 2005;25(7):846-850.

11. Yilmaz T, Cordero-Coma M. Use of bevacizumab for macular edema secondary to branch retinal vein occlusion: a systematic review. Graefes Arch Clin Exp Ophthalmol. 2012;250(6):787-793.

12. Danis RP, Sadda S, Jiao J, Li XY, Whitcup SM. Relationship between retinal thickness and visual acuity in eyes with retinal vein occlusion treated with dexamethasone implant. Retina. 2016;36(6):1170-1176.

13. Lin JM, Chiu YT, Hung PT, Tsai YY. Early treatment of severe cystoid macular edema in central retinal vein occlusion with posterior sub-tenon triamcinolone acetonide. Retina. 2007;27(2):180-189.

14. Gurram MM. Effect of posterior sub-tenon triamcinolone in macular edema due to non-ischemic vein occlusions. J Clin Diagn Res. 2013; 7(12):2821-2824.

15. Raszewska-Steglinska M, Gozdek P, Cisiecki S, Michalewska Z, Michalewski J, Nawrocki J. Pars plana vitrectomy with ILM peeling for macular edema secondary to retinal vein occlusion. Eur J Ophthalmol. 2009;19(6):1055-1062.

16. Mitchell P, Bandello F, Schmidt-Erfurth U, et al. The RESTORE study: ranibizumab monotherapy or combined with laser versus laser monotherapy for diabetic macular edema. Ophthalmology. 2011;118(4): $615-625$.

17. Hahn P, Fekrat S. Best practices for treatment of retinal vein occlusion. Curr Opin Ophthalmol. 2012;23(3):175-181.

18. Ehlers JP, Fekrat S. Retinal vein occlusion: beyond the acute event. Surv Ophthalmol. 2011;56(4):281-299.

19. Chiquet C, Bron AM, Straub M, et al. Retinal vein occlusions: therapeutic switch in macular oedema treatment with a 12-month follow-up. Ophthalmic Res. 2016;55(3):152-158.

20. Kim JY, Park SP. Comparison between intravitreal bevacizumab and triamcinolone for macular edema secondary to branch retinal vein occlusion. Korean J Ophthalmol. 2009;23(4):259-265.

21. Wu WC, Cheng KC, Wu HJ. Intravitreal triamcinolone acetonide vs bevacizumab for treatment of macular oedema due to central retinal vein occlusion. Eye (Lond). 2009;23(12):2215-2222.

22. Ip MS, Scott IU, VanVeldhuisen PC, et al. A randomized trial comparing the efficacy and safety of intravitreal triamcinolone with observation to treat vision loss associated with macular edema secondary to central retinal vein occlusion: the Standard Care vs Corticosteroid for Retinal Vein Occlusion (SCORE) study report 5. Arch Ophthalmol. 2009;127(9):1101-1114. 
23. Scott IU, Ip MS, VanVeldhuisen PC, et al. A randomized trial comparing the efficacy and safety of intravitreal triamcinolone with standard care to treat vision loss associated with macular Edema secondary to branch retinal vein occlusion: the Standard Care vs Corticosteroid for Retinal Vein Occlusion (SCORE) study report 6. Arch Ophthalmol. 2009;127(9):1115-1128.

24. Hirano Y, Ito T, Nozaki M, et al. Intraocular pressure elevation following triamcinolone acetonide administration as related to administration routes. Jpn J Ophthalmol. 2009;53(5):519-522.

25. Inatani M, Iwao K, Kawaji T, et al. Intraocular pressure elevation after injection of triamcinolone acetonide: a multicenter retrospective casecontrol study. Am J Ophthalmol. 2008;145(4):676-681.

26. Ozkiris A, Erkilic K. Complications of intravitreal injection of triamcinolone acetonide. Can J Ophthalmol. 2005;40(1):63-68.

27. Nozik RA. Periocular injection of steroids. Trans Am Acad Ophthalmol Otolaryngol. 1972;76(3):695-705.

28. Murakami T, Tsujikawa A, Miyamoto K, et al. Relationship between perifoveal capillaries and pathomorphology in macular oedema associated with branch retinal vein occlusion. Eye (Lond). 2012;26(6): 771-780.

29. Byun YJ, Roh MI, Lee SC, Koh HJ. Intravitreal triamcinolone acetonide versus bevacizumab therapy for macular edema associated with branch retinal vein occlusion. Graefes Arch Clin Exp Ophthalmol. 2010;248(7):963-971.

30. Guthoff R, Meigen T, Hennemann K, Schrader W. Comparison of bevacizumab and triamcinolone for treatment of macular edema secondary to branch retinal vein occlusion in a pair-matched analysis. Ophthalmologica. 2010;224(5):319-324.

31. Higashiyama T, Sawada O, Kakinoki M, Sawada T, Kawamura H, Ohji M. Prospective comparisons of intravitreal injections of triamcinolone acetonide and bevacizumab for macular oedema due to branch retinal vein occlusion. Acta Ophthalmol. 2013;91(4):318-324.

32. Sun Y, Qu Y. Comparison of intravitreal bevacizumab with intravitreal triamcinolone acetonide for treatment of cystoid macular edema secondary to retinal vein occlusion: a meta-analysis. Int J Ophthalmol. 2015;8(6):1234-1239.

33. Gokce G, Sobaci G, Durukan AH, Erdurman FC. The comparison of intravitreal triamcinolone and bevacizumab in patients with macular edema secondary to branch retinal vein occlusion. Clin Ophthalmol. 2014;8:355-362.
34. Kola M, Hacioglu D, Turk A, Erdol H. The effectiveness and reliability of posterior sub-tenon triamcinolone acetonide injection in branch retinal vein occlusion-related macular edema. Cutan Ocul Toxicol. 2016;35(3):185-189.

35. Beer PM, Bakri SJ, Singh RJ, Liu W, Peters GB 3rd, Miller M. Intraocular concentration and pharmacokinetics of triamcinolone acetonide after a single intravitreal injection. Ophthalmology. 2003;110(4): 681-686.

36. McAllister IL, Vijayasekaran S, Chen SD, Yu DY. Effect of triamcinolone acetonide on vascular endothelial growth factor and occludin levels in branch retinal vein occlusion. Am J Ophthalmol. 2009;147(5): 838-846, 846.e1-e2

37. Sohn HJ, Han DH, Lee DY, Nam DH. Changes in aqueous cytokines after intravitreal triamcinolone versus bevacizumab for macular oedema in branch retinal vein occlusion. Acta Ophthalmol. 2014;92(3):e217-e224.

38. Park HJ, Lee JE, Kim SI, et al. Intravitreal pharmacokinetics after posterior subtenon triamcinolone acetonide injection in vitrectomized rabbit eyes. Retina. 2014;34(4):801-806.

39. Freeman WR, Green RL, Smith RE. Echographic localization of corticosteroids after periocular injection. Am J Ophthalmol. 1987;103(3 Pt 1) 281-288.

40. Venkatesh P, Garg SP, Verma L, Lakshmaiah NC, Tewari HK. Posterior subtenon injection of corticosteroids using polytetrafluoroethylene (PTFE) intravenous cannula. Clin Exp Ophthalmol. 2002. 30(1):55-57.

41. Morley AM, Tumuluri K, Meligonis G, Collin JR. Myopathic ptosis following posterior sub-tenon's triamcinolone acetonide injection. Eye (Lond). 2009;23(3):741-742.

42. Ideta S, Noda M, Kawamura R, et al. Dehiscence of levator aponeurosis in ptosis after sub-tenon injection of triamcinolone acetonide. Can J Ophthalmol. 2009;44(6):668-672.
Clinical Ophthalmology

\section{Publish your work in this journal}

Clinical Ophthalmology is an international, peer-reviewed journal covering all subspecialties within ophthalmology. Key topics include: Optometry; Visual science; Pharmacology and drug therapy in eye diseases; Basic Sciences; Primary and Secondary eye care; Patient Safety and Quality of Care Improvements. This journal is indexed on

\section{Dovepress}

PubMed Central and CAS, and is the official journal of The Society of Clinical Ophthalmology (SCO). The manuscript management system is completely online and includes a very quick and fair peer-review system, which is all easy to use. Visit http://www.dovepress.com/ testimonials.php to read real quotes from published authors. 